\title{
The Rationale for Continuous Glucose Monitoring-based Diabetes Treatment Decisions and Non-adjunctive Continuous Glucose Monitoring Use
}

David Price and Tomas Walker

Dexcom, Inc., San Diego, California, us

\begin{abstract}
Self-monitoring of blood glucose (SMBG) is now recognised as a core component of diabetes self-management. However, there are many limitations to SMBG use in individuals with diabetes who are treated with intensive insulin regimens. Many individuals do not test at the recommended frequencies. Additionally, because SMBG only provides a blood glucose reading at a single point in time, hypoglycaemia and hyperglycaemia can easily go undetected, limiting the user's ability to take corrective action. Inaccuracies due to user error, environmental factors and weaknesses in SMBG system integrity further limit the utility of SMBG. Real-time continuous glucose monitoring (CGM) displays the current glucose, direction and velocity of glucose change and provides programmable alarms. This trending information and 'aroundthe-clock' vigilance provides a significant safety advantage relative to SMBG. No published clinical studies have evaluated outcomes when CGM is used as a replacement for SMBG; however, recent in silico studies support this indication. This article reviews the limitations of SMBG and discusses recent evidence that supports CGM-based decisions as an effective approach to managing insulin-treated diabetes.
\end{abstract}

\section{Keywords}

Continuous glucose monitoring (CGM), self-monitoring of blood glucose (SMBG), glucose monitoring, continuous subcutaneous insulin infusion (CSII), multiple-dose insulin (MDI), rate of change, glucose trend

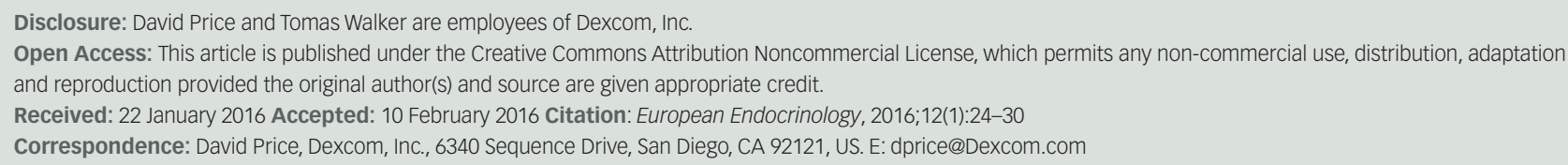

Support: The development of this manuscript was funded by Dexcom, Inc.

Type 1 diabetes (T1D) and advanced type 2 diabetes (T2D) require intensive insulin therapy in combination with frequent glucose monitoring to optimise glycaemic control. Although the value of achieving normoglycaemia has been well demonstrated, ${ }^{1}$ many individuals with insulin-treated diabetes are unable to meet established glycaemic targets without excessive and/or severe hypoglycaemia. ${ }^{2-5}$

The introduction of self-monitoring of blood glucose (SMBG) devices in the late 1970s provided a tool for assessing current glucose levels, to calculate insulin dosages and inform decisions. When first introduced, SMBG met with scepticism, as some clinicians doubted the accuracy of the devices and that patients would know how to appropriately respond to the blood glucose data. Studies soon demonstrated the utility of SMBG in limited populations ${ }^{6,7}$ and in 1993 the benefit of SMBGbased intensive diabetes management was validated in the Diabetes control and Complication Trial.

SMBG is now recognised as a core component of diabetes selfmanagement.8-11 However, given recent advances in the accuracy, reliability and usability of continuous glucose monitoring (CGM), accurate CGM systems may now be capable of replacing SMBG as a primary source of glucose information. The purpose of this report is to review the limitations of SMBG and discuss recent evidence that supports CGM-based decisions as an effective approach to managing insulin-treated diabetes. ${ }^{12,13}$

\section{Limitations of Self-Monitoring of Blood Glucose-based Decisions}

The American Diabetes Association (ADA) recommends that patients on intensive insulin regimens, multiple-dose insulin (MDI) or continuous subcutaneous insulin infusion (CSII) should consider SMBG prior to meals and snacks, occasionally following meals, at bedtime, prior to exercise, when low glucose is suspected, after treating low glucose and prior to critical tasks such as driving. For many patients, this will require testing six to 10 (or more) times daily. ${ }^{14}$ Other organisations provide similar recommendations. ${ }^{10,11}$

Many individuals do not test at the recommended frequencies. A recent survey of 16,061 participants in the T1D Exchange registry reported that $34 \%(n=3,630)$ performed SMBG zero to three times daily, ${ }^{3}$ supporting an earlier survey that found SMBG non-adherence to be as high as $60 \% .^{15}$ There are many reasons for non-adherence, including the pain and 'hassle' of testing and the perceived limited utility of the results. ${ }^{16}$ The numerous steps required to perform a blood glucose measurement, contributing to the hassle factor, are shown in Table 1. 


\section{Hypoglycaemia Remains Problematic}

Although numerous studies have shown that frequent SMBG is associated with improved glycated haemoglobin $\left(\mathrm{HbA}_{1 \mathrm{C}}\right)^{1,15-17}$ it is not associated with decreased hypoglycaemia. ${ }^{4,5}$ Even with relatively frequent testing $(9.2 \pm 2.3$ tests/day), many patients have frequent and prolonged hypoglycaemia. ${ }^{18}$ Despite use of analogue insulins and increased use of CSII, hypoglycaemia remains problematic for patients and healthcare providers. ${ }^{5}$ The T1D Exchange recently noted that $11.8 \%$ of individuals with T1D reported having severe hypoglycaemia, resulting in loss of consciousness or seizure in the past year; severe hypoglycaemia was reported by almost one in five individuals with diabetes of 40 years duration. ${ }^{19} \mathrm{~A}$ recent study by Cariou and colleagues found a self-reported rate of severe hypoglycaemia (including those requiring third-party assistance) in 31\% of individuals with T1D in the prior year. In a prospective assessment, $84.4 \%$ of individuals reported non-severe hypoglycaemia during one month, with an average of 7.1 confirmed events per patient per month. ${ }^{5}$ Further, the frequency of hypoglycaemia increased in parallel with the number of daily SMBG tests. This suggests that frequent, episodic monitoring is insufficient to prevent frequent or severe hypoglycaemia.

Obtaining glucose data via SMBG is dependent upon the user's decision to self-monitor. Accordingly, SMBG will often fail to detect nocturnal and asymptomatic hypoglycaemia. ${ }^{20,21}$ Frequent episodes of hypoglycaemia contribute to diminished hypoglycaemic awareness, and individuals with impaired awareness are at high risk for severe hypoglycaemia. ${ }^{22,23}$ Nocturnal hypoglycaemia remains a common problem and a risk factor for sudden death during sleep. ${ }^{24}$

Furthermore, frequent hypoglycaemia results in increased fear of hypoglycaemia ${ }^{25}$ and this becomes a barrier to intensifying therapy or adhering to prescribed insulin regimens. ${ }^{2,26}$ This fear often leads to poor metabolic contro ${ }^{27}$ and may result in individuals avoiding driving, and limiting exercise or sex. ${ }^{28}$

\section{Diabetes Management is Complex and Challenging}

Glucose fluctuations in T1D are often unpredictable and related to many factors including, but not limited to: variability of food absorption; insulin absorption and insulin action; effects of macro- and micronutrients; duration and intensity of exercise; stress; and, physiological changes. This challenge has been recognised since the introduction of insulin. ${ }^{29}$

The episodic nature of SMBG provides users with a blood glucose reading at a single point in time. It does not provide trend information, the direction and velocity of change in glucose or alerts. Without this information, hypoglycaemia and hyperglycaemia can easily go undetected, limiting the user's ability to take corrective action. ${ }^{30,31}$

\section{Potential for Inaccurate Blood Glucose Readings}

Because clinical decisions are based on SMBG values, the results should be accurate, to ensure safe and effective treatment decisions are made. ${ }^{32}$ Although manufacturers have made advances in strip and meter technologies to improve the performance and reliability of their systems, measurement accuracy remains suboptimal. Inaccuracy may stem from inadequate manufacturing practices and controls. ${ }^{33,34}$ Recent studies have demonstrated that $>45 \%$ of marketed SMBG systems do not meet the minimum International Organization for Standardization (ISO) accuracy standards. ${ }^{33-35}$ However, even when the most accurate

\section{Table 1: Tasks Associated with Self-Monitoring} of Blood Glucose

\author{
Blood Glucose Measurement Tasks \\ 1. Recognise the need to test \\ 2. Have the equipment including current and properly stored test strips \\ 3. Wash and dry hands \\ 4. Remove test strip and recap vial to preserve strips \\ 5. Insert test strip \\ 6. Lance fingertip (this assumes a lancet is already loaded into the lancing \\ device, otherwise, additional steps are required) \\ 7. Obtain a 'good' blood drop \\ 8. Properly apply blood drop \\ 9. Wipe excess blood, clean site \\ 10. Discard strip, lancet and wipe
}

\section{Figure 1: An Example of Uncertainty in Diabetes Management Decisions Based on Episodic Self-Monitoring of Blood Glucose}

Assume a person using intensive insulin measure their glucose 2-3 hours after a meal dose and a meal, before driving or going to sleep, and the glucose is accurately measured at $5 \mathrm{mmol} / \mathrm{L}(90 \mathrm{mg} / \mathrm{dL})$.

- Should a snack be recommended?

- Would the decision change if glucose was 4.5 or $5.5 \mathrm{mmol} / \mathrm{L}$ ?

- Would the decision change if there was knowledge about whether glucose is rising or falling?

- What is more important: the exact number or the awareness the glucose direction and rate of change?

- Would the presence of continuous glucose monitoring alerts change the recommendations?

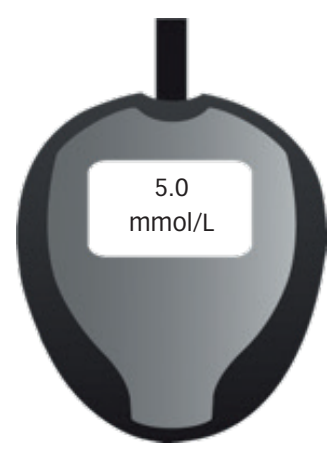

monitoring systems are used, physiological, pharmacological and human factors can compromise accuracy. ${ }^{36}$ To date, no prospective studies of SMBG accuracy in the home under 'real-world' conditions have been performed. Furthermore, even accurate measurements provide incomplete data because there is no information on the direction or rate of change (ROC). The lack of this information adds uncertainty to clinical decisions, as shown in Figure 1.

User technique can also play a significant role in the accuracy of blood glucose monitoring systems. ${ }^{36,37}$ Potential human errors include incorrect testing procedure (e.g. inadequate sample size, improper sample application or miscoding of strips) and improper strip handling (e.g. storage in high temperatures, storage outside the test strip vial and use past the expiration date). Improper cleaning of the sampling site has long been recognised as a contributing to user error. ${ }^{36,38}$ However, the most common limitation of SMBG remains failure to test.

\section{Limitations of Self-Monitoring of Blood Glucose}

SMBG-based decisions are limited based on inaccuracies and failure to test, and this is compounded by the absence of alarms and glucose trend information. These limitations complicate the inherent complexity of diabetes management and contribute to poor control. ${ }^{39}$ Recent evidence suggests that CGM-based decisions may be more effective ${ }^{12,13}$ and Table 2 highlights some of the differences between SMBG- and CGM-based decisions. 
Table 2: Comparison of Self-Monitoring of Blood Glucose and Continuous Glucose Monitoring

\section{Self-Monitoring of Blood Glucose}

- Current standard of care

- Indicated for measuring glycaemia; not approved for diabetes management

- Provides single-point data, no indication of rate or direction of glucose change

- No readings unless effort taken to measure glucose that includes lancing the skin

- May miss high or low blood glucose events

- Accuracy may be impacted by anaemia

- Accuracy may be impacted by

- May require coding

- Only detects patterns based on when glucose is measured

- May (or may not) have greater point accuracy interfering sugars on the hands

Continuous Glucose Monitoring

- Evolving standard of care

- Indicated for use in routine diabetes management decisions (DG5)

- Provides up to 288 readings a day and includes the glucose value, rate and direction of glucose change

- Readings are available with a button push

- Customisable hypoglycaemia and hyperglycaemia alerts

- Accuracy is impacted by paracetamol (acetaminophen)

- Outlier blood glucose values (from skin contaminants) used for calibration may be rejected or are averaged

- Requires calibrations

- Detects true patterns of glucose peaks and nadirs

- Point accuracy of some systems is approaching or surpassing selfmonitoring of blood glucose

\section{Advantages of Real-time Continuous Glucose Monitoring}

Real-time CGM displays the current glucose, direction and velocity of glucose change and provides programmable alarms (see Figure 2). Trending information and 'around-the-clock' vigilance provides a significant safety advantage relative to SMBG. The ability of CGM devices to alert not only the patient but also friends and family represents an area in which these devices reduce the duration and severity of hypoglycaemia. ${ }^{13}$ Some CGM devices enable users to share their glucose data, providing another level of safety.

The ability to download CGM data facilitates retrospective analysis of glucose data, allowing patients and their healthcare teams to detect glucose patterns/trends that facilitate therapeutic adjustments. This is in contrast to retrospective analysis of SMBG data, which is dependent on the timing and frequency of episodic measurements, providing an incomplete or biased understanding of glucose patterns.

\section{Clinical Efficacy of Continuous Glucose Monitoring}

Numerous studies have shown that use of CGM lowers $\mathrm{HbA}_{1 c^{\prime}}$ reduces hypoglycaemia and hyperglycaemia ${ }^{40-45}$ and improves quality of life ${ }^{46}$ in children and adults using either CSII or MDI. ${ }^{40-45,47-50}$ Similar to medication adherence, the benefit of CGM is primarily seen in adherent CGM patients, i.e. those who regularly used their devices. ${ }^{40,44}$

\section{How Patients Currently Use Real-time Continuous Glucose Monitoring} Use of Alarms, Alerts and Glucose Rate of Change Arrows

Clinical benefits of CGM use have been demonstrated in both CSII and MDI users. However, unlike with medications, improved outcomes are due to behavioural changes in response to the CGM data and not by CGM use per se. To date, few studies have specifically looked at how individuals utilise CGM data. ${ }^{13,46}$
Figure 2: Continuous Glucose Monitoring Displays Current Glucose, Glucose Direction, Alert Thresholds and Velocity of Change

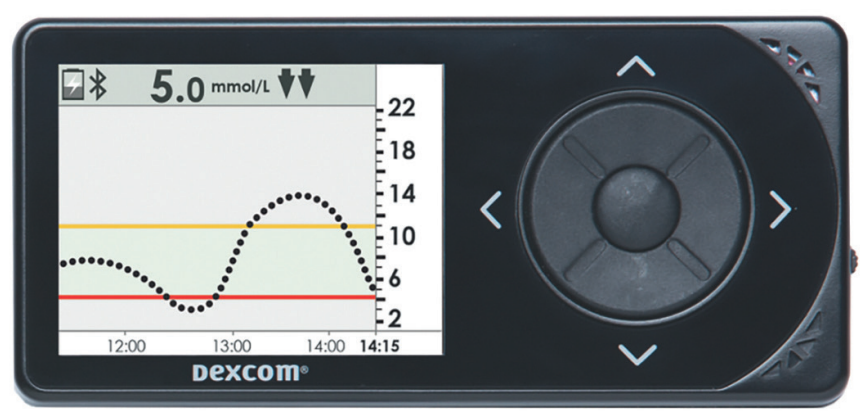

In a recent crossover study by Battelino and colleagues looking at CGM benefit among T1D individuals using CSII, investigators reported lower $\mathrm{HbA}_{1 \mathrm{c}}$ when CGM was used. ${ }^{43}$ CGM use was associated with significant increases in the mean number of daily boluses $(6.8 \pm 2.5$ versus $5.8 \pm 1.9$, $p<0.0001)$, frequency of temporary basal rates $(0.75 \pm 1.11$ versus $0.26 \pm$ $0.47, p<0.0001)$ and frequency of manual insulin suspension $(0.91 \pm 1.25$ versus $0.70 \pm 0.75, p<0.018)$. Investigators concluded that frequent insulin self-adjustments may have contributed to $\mathrm{HbA}_{1 \mathrm{c}}$ improvement.

A key feature differentiating CGM from SMBG and other emerging technologies such as 'flash' glucose monitoring (e.g. the Freestyle Libre Flash, Abbott Diabetes Care, Alameda, CA, US) is the presence of alerts and alarms. New and colleagues ${ }^{51}$ evaluated the potential of using CGM with the alerts disabled. Unlike when alerts were active, there was no significant reduction in the time spent in hypoglycaemia compared to SMBG when CGM alerts were silenced.

Pettus and colleagues reported findings from a survey of 222 T1D individuals using a CGM device for greater than one year. The objective of the survey was to assess how individuals utilise real-time CGM data and respond to their glucose information. ${ }^{13}$ Most respondents reported using a customised low glucose alert set between 3.3 and $5.5 \mathrm{mmol} / \mathrm{L}$ (60-100 $\mathrm{mg} / \mathrm{dll}$ ); only $1 \%$ of respondents relied on only the fixed $3.0 \mathrm{mmol} / \mathrm{L}$ (55 $\mathrm{mg} / \mathrm{dL}$ ) low alarm, which is unique to Dexcom CGM systems. Whereas $44 \%$ of respondents stated that they would feel symptomatic from hypoglycaemia prior to being alerted via their alarm, 33\% felt that they were alerted prior to symptoms occurring. Importantly, 70\% reported waking up at night at least once per week in response to their low glucose alert and $42 \%$ stated that in the last six months their CGM device alerted somebody around them to their hypoglycaemia alarm when they themselves were unable to respond. Since starting CGM, 78\% reported a decrease in the frequency and severity of hypoglycaemia.

Respondents also reported use of ROC information to make significant correction and mealtime dosage adjustments larger than previously recommended, ${ }^{22-54}$ resulting in speculation that respondents felt confident in the performance of their CGM device. Respondents reported that using CGM helped them achieve better control and improve their quality of life. In a subsequent report, both MDI and CSII users demonstrated similar insulin dose adjustments based on ROC. ${ }^{55}$

\section{Increasing Reliance on the Use of Continuous Glucose Monitoring Data}

Recent studies indicate that CGM users perform less frequent SMBG, suggesting that they are basing management decisions on CGM data. 
Of 11 CGM outcome studies reported since 2008, six trials did not report frequency of SMBG use; however, five trials quantified reductions in SMBG frequency (see Table 3). ${ }^{43,56-58}$ Data from the T1D Exchange registry demonstrates that most patients reduce SMBG frequency after initiating CGM. ${ }^{59}$

Decision support is enhanced by CGM; a user simply needs to press a button to see a glucose value and trend. Each screen view provides an opportunity to evaluate current glucose management. The frequency and benefit of CGM receiver interaction were reported in 2008 by Bailey and colleagues. ${ }^{00}$ They examined the number of 'screen views' seen in subjects in a CGM trial, dividing the views into frequency quartiles. Screen views ranged from an average of 12.2 per day in the bottom quartile to 47.2 per day in the top quartile. Subjects in the top quartile had improvement in $\mathrm{HbA}_{1 \mathrm{c}}$ compared with those in the bottom quartile $(p<0.0001)$.

\section{Current Dexcom Continuous Glucose Monitoring Technology Can Support Safe and Effective Treatment Decision-making}

A common metric for assessment of accuracy of both SMBG and CGM devices is the aggregate mean absolute relative difference (MARD) between all temporally matched device data and reference measurements. Recent independent studies have shown that MARD values for current SMBG systems range from $4.4 \%$ to $13.4 \%$ when evaluated by independent investigators under optimal conditions, using fresh test strips and performed by trained professionals using split aliquot samples. ${ }^{61-63}$ Although CGM users were historically instructed to base clinical decisions on SMBG values, CGM technologies have made significant improvements and are approaching SMBG accuracy. To date, no published clinical studies have evaluated outcomes when CGM is used as a replacement for SMBG. However, recent in silico studies support this indication. ${ }^{12,64,65}$

\section{Impact on Hypoglycaemia and Hyperglycaemia} A Monte Carlo simulation compared the impact of determining a premeal insulin dose using SMBG glucose value versus a CGM glucose value and ROC on the frequency of post-meal hypoglycaemia $(3.8 \mathrm{mmol} / \mathrm{L}$ $[<70 \mathrm{mg} / \mathrm{dL}])$, and hyperglycaemia (>10 mmol/L [>180 mg/dl]). ${ }^{64}$ This simulation did not include use of alerts and alarms and was not based on current CGM technology. Both glucose monitoring methods performed similarly when glucose levels were stable. However, at declining ROC, SMBG-based decisions resulted in a higher frequency of hypoglycaemia and a lower frequency of hyperglycaemia compared with CGM-based decisions. This is because CGM users reduced their insulin dose in response to falling glucose. The opposite was true at rising glucose when CGM users increased their insulin dosages, resulting in decreased hyperglycaemia rates and increased hypoglycaemia rates relative to decisions based on SMBG. Again, this simulation did not include alerts, which would serve to mitigate hypoglycaemia. A follow-up simulation confirmed that use of low glucose alerts minimised hypoglycaemia. ${ }^{66}$

\section{Safe Insulin Dosing Using Continuous Glucose Monitoring Data}

In a recent in silico study, ${ }^{12}$ investigators assessed the level of accuracy required for safe insulin dosing using CGM data. In one scenario, the current CGM value, with and without ROC adjustments, was used to make insulin dosing decisions. In a second scenario, dosing decisions utilised threshold alerts at $3.8 \mathrm{mmol} / \mathrm{L}(70 \mathrm{mg} / \mathrm{dL})$ and $10.0 \mathrm{mmol} / \mathrm{L}$ (180 mg/dL) with and without ROC adjustments. Each modality was

\section{Table 3: Reduction in Self-Monitoring of Blood Glucose use Post Continuous Glucose Monitoring Initiation}

\begin{tabular}{|c|c|c|c|c|}
\hline Reference & $\mathrm{N}$ & $\begin{array}{l}\text { Duration of } \\
\text { Continuous } \\
\text { Glucose } \\
\text { Monitoring } \\
\text { Use }\end{array}$ & $\begin{array}{l}\text { Self-Monitoring } \\
\text { of Blood } \\
\text { Glucose } \\
\text { Reduction } \\
\text { from Baseline }\end{array}$ & Comments \\
\hline $\begin{array}{l}\text { Direct Net } \\
\text { Study Group, } \\
2008\end{array}$ & $\mathrm{~N}=27$ & 3 months & $\begin{array}{l}>40 \% \text { reduction } \\
(p=0.16) \text { NS }\end{array}$ & $\begin{array}{l}\text { Compared run-in to } \\
\text { completion }\end{array}$ \\
\hline $\begin{array}{l}\text { Riveline } \\
\text { et al., } 2012\end{array}$ & $\mathrm{~N}=178$ & 12 months & $\begin{array}{l}>50 \% \text { reduction } \\
(p<0.0001)\end{array}$ & $\begin{array}{l}\text { Subjects were trained } \\
\text { in aggressive DM self- } \\
\text { management }\end{array}$ \\
\hline $\begin{array}{l}\text { Battelino } \\
\text { et al., } 2012\end{array}$ & $N=153$ & $\begin{array}{l}6 \text { months } \\
\text { crossover }\end{array}$ & $\begin{array}{l}0.6 \text { tests } / \text { day } \\
(p<0.0001)\end{array}$ & $\begin{array}{l}\text { Removal of CGM resulted } \\
\text { in loss of metabolic } \\
\text { benefit }\end{array}$ \\
\hline $\begin{array}{l}\text { Bergenstal } \\
\text { et al., } 2013\end{array}$ & $N=247$ & 3 months & $\begin{array}{l}0.6 \text { tests/day } \\
\text { (not significant) }\end{array}$ & $\begin{array}{l}\text { Identical reported } \\
\text { reduction in SMBG in } \\
\text { both SAP and LGS }\end{array}$ \\
\hline $\begin{array}{l}\text { New } \\
\text { et al., } 2015\end{array}$ & $\mathrm{~N}=145$ & 100 days & $\begin{array}{l}>50 \% \text { reduction } \\
(p<0.0001)\end{array}$ & $\begin{array}{l}\text { Reduction noted in both } \\
\text { CGM groups }\end{array}$ \\
\hline
\end{tabular}

CGM = continuous glucose monitoring; $D M=$ diabetes mellitus; $L G S=$ Low-Glucose Suspend; SAP = Sensor Augmented Pump

\section{Figure 3: Hypoglycaemic and Hyperglycaemic Outcomes from Treatment Modalities}
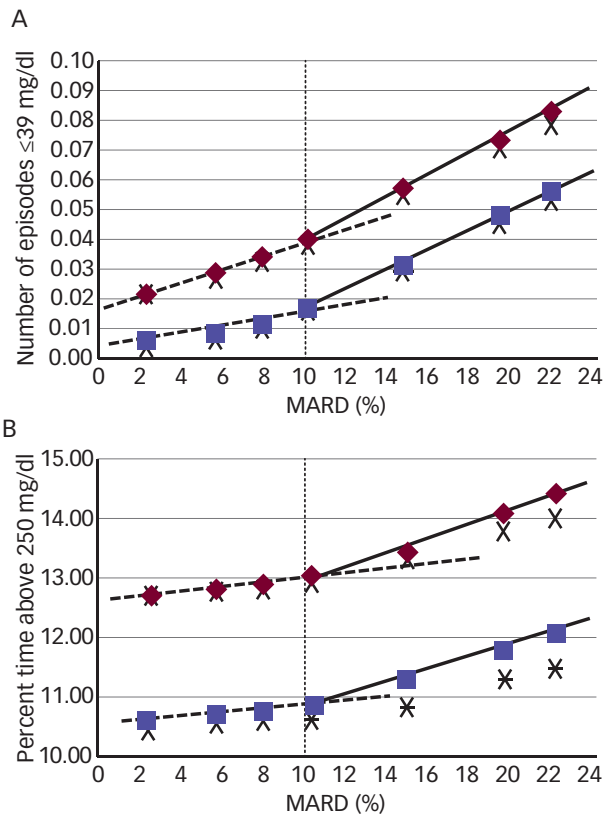

- CGM value XCGM value + ROC Threshold * Threshold + ROC

$C G M=$ continuous g/ucose monitoring; $M A R D=$ mean absolute relative difference, $R O C=$ rate of change. Source: Modified from Kovatchev $B P$, et al. Diabetes Technol Ther, 2015; 17:177-86'12

assessed at seven levels of sensor accuracy, as measured by MARD, ranging from $3 \%$ to $22 \%$.

As shown in Figure $3 A$, the frequency of blood glucose episodes $<2.1 \mathrm{mmol} / \mathrm{L}(39 \mathrm{mg} / \mathrm{dL})$ increased with sensor error, displaying a notable slope change at 10\% MARD. Similar increases were seen in the percentage of time spent at glucose levels $>13.8 \mathrm{mmol} / \mathrm{L}(250 \mathrm{mg} / \mathrm{dL})$ 
(see Figure 3B). Most importantly, significant benefits were seen when threshold alarms were used in conjunction with dose adjustments based on glucose ROC; an option that is not possible with SMBG Based on these findings, investigators concluded that use of CGM data for insulin dosing decisions is feasible below a 10\% MARD. Moreover, improvements in sensor accuracy below the 10\% MARD threshold would not contribute substantively to better glycaemic outcomes. This analysis also highlighted the pivotal role CGM alerts play in improving outcomes.

\section{Improving Glycaemic Control with Continuous Glucose Monitoring with Alarms and Corrections for Glucose Trend}

An assessment of SMBG versus CGM-based decisions was performed in a validated model using in-silico patients and demonstrated that the use of the additional information provided by CGM (e.g. trend and hypoglycaemic/hyperglycaemic alarms) resulted in a statistically significant ( 9\%) increase in time spent euglycaemic 3.8-10.0 mmol/L (70-180 mg/dL) when compared with dosing based on SMBG values. ${ }^{65}$ Investigators found that use of CGM in place of SMBG for insulin bolus calculation did not adversely impact the safety or effectiveness of dosing decisions. Moreover, the combination of the use of CGM glucose values, trends and alerts significantly improves glycaemic control compared with SMBG-based therapy decisions.

\section{Non-adjunctive Criteria for Continuous Glucose Monitoring-based Diabetes Management}

Due to a marked improvement in accuracy, ${ }_{1}^{7,68}$ the Dexcom G5 Mobile (DG5) is now indicated to replace SMBG for routine diabetes treatment decisions outside the US (receiving the Conformité Européenne [CE] mark). The following is a summary of the indication statement included in the CE mark document. . $^{6}$

- The DG5 is indicated for the management of diabetes in persons aged two years and older.

- The DG5 is designed to replace finger-stick blood glucose testing for diabetes treatment decisions.

- The DG5 aids in the detection of episodes of hyperglycaemia and hypoglycaemia, facilitating both acute and long-term therapy adjustments.

- Interpretation of the DG5 results should be based on the glucose trends and several sequential readings over time.

\section{Evidence of Accuracy and Efficacy}

Christiansen and colleagues ${ }^{70}$ compared the accuracy and performance of a new-generation CGM system, Dexcom G4 Platinum (G4P) with a previous-generation device, Dexcom SevenPlus (DSP). Investigators found that the aggregate MARD for the G4P sensor was $13 \%$ compared with $16 \%$ for DSP $(p<0.0001)$; approximately $50 \%$ of the G4P sensors had a MARD $<12.5 \%$ compared with $14 \%$ for the DSP sensors ( $p=0.028$ ). In collaboration with an academic research group further refinements were made to the G4P algorithm. ${ }^{71}$

In 2015, Bailey and colleagues reported their assessment of the performance of the modified G4P system with the addition of a new calibration algorithm called 'Software 505'. This algorithm is found in the DG5.67 In comparison with the laboratory reference method, the system achieved a MARD of $9 \%$. The Mean Absolute Difference (MAD) for the modified G4P system was $0.35 \mathrm{mmol} / \mathrm{L}(6.4 \mathrm{mg} / \mathrm{dL})$ within hypoglycaemia ranges $\leq 3.8 \mathrm{mmol} / \mathrm{L}(70 \mathrm{mg} / \mathrm{dl})$. Assessment of individual sensor performance, which is a better reflection of the patient experience, found few outlier sensors. Among the 51 sensors, only one had $>20 \%$ MARD (on day one) and three sensors had $>15 \%$ MARD. Other CGM devices are approaching the 10\% MARD accuracy target. $^{72,73}$ One other device, the Freestyle Libre Flash glucose monitoring system (Abbott Diabetes Care, Alameda, CA, USA), received the CE mark as a replacement for SMBG when dosing insulin except when glucose is changing rapidly or when hypoglycaemic; however, lack of alerts/alarms may limit its utility in detecting immediate or impending hypoglycaemia or hyperglycaemia. Other CGM systems, such as the Medtronic Veo or 640G are integrated into insulin pumps and have regulatory approval for the system to suspend insulin based on CGM data but do not allow users to base clinical decisions primarily on CGM values.

Peyser and colleagues recently assessed the modified G4P system to determine the optimum setting of hypoglycaemic alerts. Results of the study showed that when the hypoglycaemic alert was set at $4.4 \mathrm{mmol} / \mathrm{L}(80 \mathrm{mg} / \mathrm{dL})$, the device provided an alert for biochemical hypoglycaemia $(3.8 \mathrm{mmol} / \mathrm{L}[70 \mathrm{mg} / \mathrm{dL}])$ within ten minutes in $95 \%$ of instances and at least a ten-minute advance warning before the cognitive impairment threshold $(3.0 \mathrm{mmol} / \mathrm{L}[55 \mathrm{mg} / \mathrm{dL}]$ ) in $91 \%$ of instances in the study ${ }^{68}$ These findings demonstrate that use of a $4.4 \mathrm{mmol} / \mathrm{L}(80 \mathrm{mg} / \mathrm{dL})$ threshold setting for hypoglycaemic alerts on the DG5 may provide patients with an actionable warning of impending hypoglycaemia before the onset of cognitive impairment.

\section{Limitations of Continuous Glucose Monitoring}

Despite ongoing improvements in CGM technology, challenges remain which impact sensor reliability and performance. Signal disruptions can occur from a variety of causes, including micro-motion of the sensor, local blood flow changes and wireless connectivity problems. These can result in data gaps that may impact alerts and limit acute management decisions.

Sensor compression can occur when individuals lay on top of their sensor for a prolonged period, such as when sleeping. These signal disruptions typically result in a false low CGM glucose and are not likely to have safety-related implications. ${ }^{74}$ Additionally, sensor motion can result in inflammation around the sensor site. ${ }^{75-78}$ Furthermore, a foreign body response occurs and can be influenced by the sensor shape, ${ }^{79}$ size $^{80}$ and surface typography. ${ }^{81}$

Lag time between interstitial glucose and blood glucose remains a consideration when basing decisions on CGM. The lag time between when glucose concentration changes appear in the blood and when they appear in the interstitial fluid can be variable between CGM systems. ${ }^{82,83}$ This is influenced by sensor geometry, sensor membranes, algorithmic filtering, direction and ROC. ${ }^{82,83}$ The DG5 demonstrated an average lag time of five to six minutes during clinical testing. ${ }^{67}$

Other factors which can adversely impact sensor accuracy and performance include interference from medications containing paracetamol (acetaminophen), ${ }^{84}$ failure to calibrate according to manufacturer recommendations and use in populations outside of the current indications.

To ensure safe and efficacious CGM use for treatment decisions, users should adhere to the following safety guidelines. ${ }^{69}$

- If the CGM device does not display a sensor glucose reading or is displaying inconsistent readings, users should perform a finger-stick blood glucose value for diabetes treatment decisions. 
- Users should make diabetes treatment decisions considering the combination of the sensor glucose reading, trend arrow, and trend graph.

- If glucose alerts and readings do not match symptoms or expectations, users should obtain a finger-stick blood glucose value to make diabetes treatment decisions.

The benefits of CGM-based decisions are realised only when there is action, such as modification of lifestyle or medication, based on the glucose results. This requires both the patient and the clinician to know how to monitor, interpret and respond appropriately to acute glucose excursions and patterns of glycaemia. Table 4 presents criteria for effective use of glucose data.

\section{Summary}

Glucose monitoring in diabetes is integral to achieving desired glycaemic control. The introduction of SMBG devices in the late 1970s provided an improved but imperfect tool for diabetes management. Numerous factors can significantly limit the utility of SMBG for decision-making.

New evidence demonstrates that CGM-based treatment may be a more effective approach to manage diabetes. 12,13,64,65 As reported by Pettus and colleagues, many CGM users report substantial safety benefits with CGM alerts. Further, they use glucose ROC information to make significant modifications to many aspects of their diabetes management. ${ }^{13}$

The clinical benefit of CGM technology is dependent upon both the accuracy, $_{12}$ persistence of use ${ }^{40,44}$ and presence of alerts/alarms, ${ }^{13}$ CGM accuracy can impact both the clinical utility ${ }^{12,64,65}$ and patient acceptance. ${ }^{85-88}$ It is likely that a highly accurate CGM that reliably provides alerts will engender trust.

One CGM system has achieved a level of accuracy where the glucose value can be used for clinical decision-making. This could spare patients the hassle and pain of additional finger-sticks and provide them more actionable glucose information. The safety of using current CGM technology as the primary source of glucose data is being evaluated in the ongoing REPLACE-BG study (NCT02258373). ${ }^{89}$ Further studies comparing CGM-based decisions and non-adjunctive CGM use

\section{Table 4: Criteria for Effective Utilisation of Glucose Monitoring Data}

\section{Provider Requirements}

- Establish realistic goals with patients

- Encourage the adoption of technologies which inform better clinical decisions but communicate limitations

- Review device use and requirements with patients

- For continuous glucose monitoring, discuss the value of alerts and alarms, assist in defining settings, and modify to avoid 'alarm fatigue'

- Review the patient's glucose data at every clinical visit and discuss therapeutic and behaviour changes

- Provide encouragement and help patients overcome barriers to glucose monitoring
Patient Requirements

- Align your goals with your clinician

- Work with your clinician to establish realistic expectations of device performance; understand limitations

- Perform recommended blood glucose monitoring, whether used for treatment decisions or calibration

- For continuous glucose monitoring, use alerts and alarms to manage and prevent hypo- and hyperglycaemia

- Reflect back on your glucose data to learn what worked well and what did not. Adjust therapy and behaviour based on the glucose data, per your clinician

- Recognise that for glucose monitoring to improve control, the device must be used; discuss and overcome barriers are needed in specific populations, such as children, older individuals, newly diagnosed individuals, pregnant women and people who are prone to severe hypoglycaemia.

Given the growing incidence of diabetes (T1D and T2D) ${ }^{\circ 0}$ and the persistent problems associated with hypoglycaemia and hyperglycaemia, new tools are needed. In order to reduce the global burden of diabetes the consequences of poor glucose control must be addressed and the individual's burden in managing their disease must be reduced. CGMbased decisions, by providing alerts and showing an individual where the glucose was and where it is going, removes some of the uncertainty and risks of diabetes management. Minimising finger-sticks further unencumbers the individual. Using accurate CGM system to replace SMBG for diabetes management decisions should facilitate greater acceptance and perseverance with CGM and lead to better long-term outcomes. 1. Diabetes Control and Complications Trial Study Group The effect of intensive treatment of diabetes on the
development and progression of long-term complications in insulin-dependent diabetes mellitus, N Engl J Med in insulin-dependent

2. Cryer PE, Hypoglycemia: still the limiting factor in the glycemic management of diabetes, Endocr Pract, 2008;14:750-6.

3. Miller KM, Foster NC, Beck RW, et al., Network TDEC: Current state of type 1 diabetes treatment in the U.S.: updated data from the T1D Exchange clinic registry, Diabetes Care 2015;38:971-8.

4. Giorda CB, Ozzello A, Gentile S, et al., Incidence and risk factors for severe and symptomatic hypoglycemia in type factors for severe and symptomatic hypoglycemia in type 1 diabetes. Results

5. Cariou B, Fontaine P, Eschwege E, et al., Frequency and predictors of confirmed hypoglycaemia in type 1 and insulin-treated type 2 diabetes mellitus patients in a real-life setting: results from the DIALOG study, Diabetes Metab, 2015;41:116-25.

6. Walford S, Gale EA, Allison SP, Tattersall RB, Self-monitoring of blood-glucose. Improvement of diabetic control, Lancet, 1978; $1: 732-5$

7. Sonksen PH, Judd SL, Lowy C, Home monitoring of bloodglucose. Method for improving diabetic control, Lancet, 1978;1:729-32.

8. International Diabetes Federation, Global IDF/ISPAD Guideline for Diabetes in Childhood and Adolescence, Brussels: International Diabetes Federation, 2011

9. Standards of Medical Care in Diabetes - 2016, Diabetes Care 2016:39(Supp 1):S1-S112.

10. Grunberger G, Bailey T, Camacho PM, et al., Glucose
Monitoring Consensus Conference Writing C: Proceedings from the american association of clinical endocrinologists and american college of endocrinology consensus conference on glucose monitoring, Endocr Pract 2015;21:522-33.

11. National Institute for Health and Care Excellence (NICE), Type 1 diabetes in adults: diagnosis and management. NICE guidelines (NG17), 2015. Available at: www.nice.org.uk/ guidance/ng17/chapter/1-Recommendations\#blood-glucosemanagement-2 (accessed 18 December, 2015)

12. Kovatchev $B P$, Patek SD, Ortiz EA, Breton MD, Assessing sensor accuracy for non-adjunct use of continuous glucose monitoring, Diabetes Technol Ther, 2015;17:177-86.

13. Pettus J, Price DA, Edelman SV, How Patients with Type 1 Diabetes Translate Continuous Glucose Monitoring Data into Diabetes Management Decisions, Endocr Pract, 2015:21:613-20.

14. American Diabetes A, (6) Glycemic targets, Diabetes Care, 2015;38(Suppl):S33-40.

15. 15. Karter AJ, Ackerson LM, Darbinian JA, et al., Selfmonitoring of blood glucose levels and glycemic control: the Northern California Kaiser Permanente Diabetes registry, Am J Med, 2001;111:1-9.

16. Fisher WA, Kohut T, Schachner H, Stenger P, Understanding self-monitoring of blood glucose among individuals with type 1 and type 2 diabetes: an information-motivation-behavioral skills analysis, Diabetes Educ, 2011;37:85-94.

17. Nathan DM, McKitrick C, Larkin M, et al., Glycemic control in diabetes mellitus: have changes in therapy made difference?, Am J Med, 1996;100:157-63.

18. Bode BW, Schwartz S, Stubbs HA, Block JE, Glycemic characteristics in continuously monitored patients with type 1 and type 2 diabetes: normative values, Diabetes Care,
2005:28:2361-6

19. Weinstock RS, Xing D, Maahs DM, et al., Severe hypoglycemia and diabetic ketoacidosis in adults with type 1 diabetes: results from the T1D Exchange clinic registry, J Clin Endocrino Metab, 2013;98:3411-9.

20. The DCCT Research Group, Epidemiology of severe hypoglycemia in the diabetes control and complications trial. The DCCT Research Group, Am J Med, 1991;90:450-9.

21. Juvenile Diabetes Research Foundation Continuous Glucose, Prolonged Monitoring Study Prolonged nocturnal hypoglycemia is common during 12 months of continuous glucose monitoring in children and adults with type 1 diabetes, Diabetes Care, 2010;33:1004-8.

22. Bolli GB, Hypoglycaemia unawareness, Diabetes Metab, 1997;23(Suppl 3):29-35.

23. Gold AE, Macleod KM, Frier BM, Frequency of severe hypoglycemia in patients with type I diabetes with impaired awareness of hypoglycaemia, Diabetes Care, 1994;17:697-703.

24. Gill GV, Woodward A, Casson IF, Weston PJ, Cardiac arrhythmia and nocturnal hypoglycaemia in type 1 diabetes--the 'dead in bed' syndrome revisited, Diabetologia, 2009;52:42-5

25. Anderbro T, Amsberg S, Adamson U, et al., Fear of hypoglycaemia in adults with Type 1 diabetes, Diabet Med, 2010;27:1151-8.

26. Riddle $M C$, The underuse of insulin therapy in North America, Diabetes Metab Res Rev, 2002;18(Suppl 3):S42-9.

27. Wild $D$, von Maltzahn $R$, Brohan E, et al., A critical review of the literature on fear of hypoglycemia in diabetes: Implications for diabetes management and patient education, Patient Educ Couns, 2007:68:10-5

28. Weitzman ER, Kelemen S, Quinn M, et al., Participatory surveillance of hypoglycemia and harms in an online social 
network, JAMA Internal Medicine, 2013;173:345-51.

29. Joslin $\mathrm{E}$, Gray H, Root $\mathrm{H}$, Insulin in hospital and home, J Metab Res, 1922;2:651-99.

30. Weber KK, Lohmann T, Busch K, et al., High frequency of unrecognized hypoglycaemias in patients with Type 2 diabetes is discovered by continuous glucose monitoring, Exp Clin Endocrinol Diabetes, 2007;115:491-4.

31. Boland $\mathrm{E}, \mathrm{Monsod} \mathrm{T}$, Delucia $\mathrm{M}$, et al., Limitations of conventional methods of self-monitoring of blood glucose: lessons learned from 3 days of continuous glucose sensing in pediatric patients with type 1 diabetes, Diabetes Care, 2001;24:1858-62.

32. Clarke WL, The original Clarke Error Grid Analysis (EGA), Diabetes Technol Ther, 2005;7:776-9.

33. Freckmann $\mathrm{G}$, Baumstark $\mathrm{A}$, Jendrike $\mathrm{N}$, et al., System accuracy evaluation of 27 blood glucose monitoring systems according to DIN EN ISO 15197, Diabetes Technol Ther, 2010;12:221-31.

34. Brazg RL, Klaff $\mathrm{L}$, Parkin CG, Performance variability of seven commonly used self-monitoring of blood glucose systems: clinical considerations for patients and providers, I Diabetes Sci Technol, 2013;7:144-52.

35. DIN EN ISO 15197, In Vitro Diagnostic Test Systems Requirements for Blood Glucose Monitoring Systems for SelfTesting in Managing Diabetes Mellitus (ISO 15197), Brussels: European Committee for Standardization, 2003.

36. Ginsberg BH, Factors affecting blood glucose monitoring: sources of errors in measurement, J Diabetes Sci Technol, 2009:3:903-13.

37. Bergenstal R, Pearson J, Cembrowski GS, et al., Identifying variables associated with inaccurate self-monitoring of blood glucose: proposed guidelines to improve accuracy, Diabetes Educ, 2000;26:981-9.

38. Hirose T, Mita T, Fujitani Y, Kawamori R, Watada H, Glucose monitoring after fruit peeling: pseudohyperglycemia when neglecting hand washing before fingertip blood sampling: wash your hands with tap water before you check blood glucose level, Diabetes Care, 2011;34:596-7.

39. Klonoff DC, Prahalad P, Performance of Cleared Blood Glucose Monitors, J Diabetes Sci Technol, 2015;9:895-10.

40. Juvenile Diabetes Research Foundation Continuous Glucose Monitoring Study Group, Effectiveness of continuous glucose monitoring in a clinical care environment: evidence from the Juvenile Diabetes Research Foundation continuous glucose Juvenile Diabetes Research Foundation continuous glucose

41. Raccah $D$, Sulmont $V$, Reznik $Y$, et al., Incremental value of continuous glucose monitoring when starting pump therapy in patients with poorly controlled type 1 diabetes: the RealTrend study, Diabetes Care, 2009;32:2245-50.

42. O'Connell MA, Donath S, O'Neal DN, et al., Glycaemic impact of patient-led use of sensor-guided pump therapy in type 1 diabetes: a randomised controlled trial, Diabetologia, 2009;52:1250-7.

43. Battelino T, Conget I, Olsen B, et al., The use and efficacy of continuous glucose monitoring in type 1 diabetes treated with insulin pump therapy: a randomised controlled trial, Diabetologia, 2012;55:3155-62.

44. Battelino T, Phillip M, Bratina N, et al., Effect of continuous glucose monitoring on hypoglycemia in type 1 diabetes, Diabetes Care 2011:34:795-800.

45. Frontino G, Bonfanti R, Scaramuzza A, et al., Senso augmented pump therapy in very young children with type 1 diabetes: an efficacy and feasibility observational study, Diabetes Technol Ther, 2012;14:762-4.

46. Hommel E, Olsen B, Battelino T, et al., Impact of continuous glucose monitoring on quality of life, treatment satisfaction and use of medical care resources: analyses from the SWITCH study, Acta Diabetol, 2014;51:845-51.

47. Buse JB, Kudva YC, Battelino T, et al., Effects of sensoraugmented pump therapy on glycemic variability in well-controlled type 1 diabetes in the STAR 3 study, Diabetes Technol Ther, 2012:14:644-7.

48. Hermanns N, Schumann B, Kulzer B, Haak T, The impact of continuous glucose monitoring on low interstitial glucose values and low blood glucose values assessed by pointof-care blood glucose meters: results of a crossover trial, $J$ of-care blood glucose meters: results
Diabetes Sci Technol, 2014;8:516-22.

49. Yoo HJ, An HG, Park SY, et al., Use of a real time continuous glucose monitoring system as a motivational device for poorly controlled type 2 diabetes, Diabetes Res Clin Pract, 2008;82:73-9

50. Vigersky RA, Fonda SJ, Chellappa M, et al., Short- and longterm effects of real-time continuous glucose monitoring in patients with type 2 diabetes, Diabetes Care, 2012;35:32-8.

51. New JP, Ajjan R, Pfeiffer AF, Freckmann G, Continuous glucose monitoring in people with diabetes: the randomized controlled Glucose Level Awareness in Diabetes Study (GLADIS), Diabet Med, 2015:32:609-17.

52. The JDRF-CGM Study Group, The JDRF randomized clinical trial to assess the efficacy of real-time continuous glucose monitoring in the management of type 1 diabetes: research design and methods, Diabetes Technol Ther, 2008:10:310-21.

53. Buckingham B, Xing D, Weinzimer S, et al., Use of the DirecNet Applied Treatment Algorithm (DATA) for diabetes management with a real-time continuous glucose monitor (the Freestyle Navigator), Pediatr Diabetes, 2008;9:142-7.

54. Hirsch IB, Clinical review: Realistic expectations and practica use of continuous glucose monitoring for the endocrinologist, I Clin Endocrinol Metab, 2009;94:2232-8.

55. Pettus J, Edelman SV, Use of glucose rate of change arrows to adjust insulin therapy among individuals with tyhpe 1 diabetes who use continuous glucose monitoring (CGM), Diabetes Technol Ther, 2016;18(Suppl 2):34-42.

56. Weinzimer S, Xing D, Tansey M, et al., Freestyle navigator continuous glucose monitoring system use in children with type 1 diabetes using glargine-based multiple daily dose regimens: results of a pilot trial Diabetes Research in Children Network (DirecNet) Study Group, Diabetes Care, 2008;31:525-7.

57. Riveline JP, Schaepelynck P, Chaillous L, et al., Assessment of patient-led or physician-driven continuous glucose monitoring in patients with poorly controlled type 1 diabetes using basal-bolus insulin regimens: a 1-year multicenter study, Diabetes Care, 2012;35:965-71.

58. Bergenstal RM, Klonoff DC, Garg SK, Threshold-based insulinpump interruption for reduction of hypoglycaemia, N Eng/ 」 Med, 2013;369:224-32

59. Wong JC, Foster NC, Maahs DM, et al., Real-time continuous glucose monitoring among participants in the T1D Exchange clinic registry, Diabetes Care, 2014:37:2702-9.

60. Bailey TS, Zisser HC, Garg SK, Reduction in hemoglobin A1C with real-time continuous glucose monitoring: results from 12-week observational study, Diabetes Technol Ther, 2007:9:203-10.

61. Link M, Schmid C, Pleus S, et al., System Accuracy Evaluation of Four Systems for Self-Monitoring of Blood Glucose Following ISO 15197 Using a Glucose Oxidase and a Hexokinase-Based Comparison Method, J Diabetes Sci Technol, 2015;9:1041-50

62. Tack C, Pohlmeier H, Behnke T, et al., Accuracy evaluation of five blood glucose monitoring systems obtained from the pharmacy: a European multicenter study with 453 subjects, Diabetes Technol Ther, 2012;14:330-7.

63. Zueger T, Schuler V, Stettler C, et al., Assessment of three frequently used blood glucose monitoring devices in clinica routine, Swiss Med WKIy, 2012;142:w13631.

64. Price D, Nandagopalan S, Simulating the glycemic impact of insulin dose determinations using continuous glucose of insulin dose determinations using continuous g
monitoring data vs. self-monitored blood glucose, Diabetologia, 2014;57(S1):954(A)

65. Vettoretti M, Facchinetti A, Sparacino G, Cobelli C, Simulation of patient decision-making to test safety and effectiveness of CGM sensor for non-adjunctive use in type 1 diabetes: SMBGvs CGM-based therapies, 15th Annual Diabetes Technology Meeting, October 22-24, Bethesda, MA.

66. Jepson L, Bhavaraju1 N, Price D, Simulating The Safety Of Dosing Decisions Using CGM: A Direct Comparison of Dexcom CGM Systems Using 505 Software Algorithm and Blood Glucose Measurements, Diabetes Technol Ther, 2016;18(Suppl 1):A183.

67. Bailey TS, Chang A, Christiansen M, Clinical accuracy of a continuous glucose monitoring system with an advanced algorithm, J Diabetes Sci Technol, 2015:9:209-14.

68 Peyser TA, Nakamura K Price D, et al, Hypoglycemic Accuracy and Improved Low Glucose Alerts of the Latest Dexcom G4 Platinum Continuous Glucose Monitoring System, Diabetes Technol Ther, 2015;17:548-54.

69. Dexcom G5 Mobile User Guide, San Diego: Dexcom Inc., 2015.
70. Christiansen M, Bailey T, Watkins E, et al., A New-Generation Continuous Glucose Monitoring System: Improved Accuracy and Reliability Compared with a Previous-Generation System Diabetes Technol Ther, 2013;15(10):881-8.

71. Garcia A, Rack-Gomer AL, Bhavaraju NC, et al., Dexcom G4AP an advanced continuous glucose monitor for the artificial pancreas, J Diabetes Sci Technol, 2013;7:1436-45.

72. Bailey TS, Ahmann A, Brazg R, et al., Accuracy and acceptability of the 6-day Enlite continuous subcutaneous glucose sensor, Diabetes Technol Ther, 2014;16:277-83

73. Bailey T, Bode BW, Christiansen MP et al. The Performance and Usability of a Factory-Calibrated Flash Glucose Monitoring System, Diabetes Technol Ther, 2015;17:787-94.

74. Best JH, Boye KS, Rubin RR, et al., Improved treatment satisfaction and weight-related quality of life with exenatid once weekly or twice daily, Diabet Med, 2009;26:722-8.

75. Rosenstock J, Ahmann AJ, Colon G, et al., Advancing Insulin Therapy in Type 2 Diabetes Previously Treated With Glargine Plus Oral Agents: Prandial premixed (insulin lispro protamine suspension/lispro) versus basal/bolus (glargine/lispro) therapy, Diabetes Care, 2008;31:20-5.

76. 76. Jenkins AL, Kacinik V, Lyon MR, Wolever TM, Reduction of postprandial glycemia by the novel viscous polysaccharide $P G X$, in a dose-dependent manner independent of food form, J Am Coll Nutr, 2010;29:92-8.

77. Grover GJ, Koetzner L, Wicks J, et al., Effects of the soluble fiber complex PolyGlycopleX(R) (PGX(R)) on glycemic control, insulin secretion, and GLP-1 levels in Zucker diabetic rats, Life Sci, 2011;88:392-9.

78. Barengolts El, Burke BV, Duckworth WC, et al., Adoption of a new technology in a Veterans Affairs national formulary system with local implementation: the insulin glargine example, Manag Care Interface, 2007;20:37-44.

79. Handelsman Y, Mechanick JI, Blonde L, et al., American Association of Clinical Endocrinologists Medical Guidelines for Clinical Practice for developing a diabetes mellitus comprehensive care plan, Endocr Pract, 2011;17(Suppl 2):1-53.

80. Kvist PH, Iburg T, Aalbaek B, et al., Biocompatibility of an enzyme-based, electrochemical glucose sensor for shortterm implantation in the subcutis, Diabetes Technol Ther 2006;8:546-59.

81. Ashwell SG, Bradley C, Stephens JW, et al., Treatment satisfaction and quality of life with insulin glargine plus insulin lispro compared with NPH insulin plus unmodified human insulin in individuals with type 1 diabetes, Diabetes Care 2008;31:1112-7.

82. Kamath A, Mahalingam A, Brauker J, Analysis of time lags and other sources of error of the DexCom SEVEN continuous glucose monitor, Diabetes Technol Ther, 2009;11:689-95.

83. Schmelzeisen-Redeker G, Staib A, Strasser M, et al., Overview of a novel sensor for continuous glucose monitoring, J Diabetes Sci Technol, 2013;7:808-14.

84. Maahs DM, Desalvo D, Pyle L, et al., Effect of acetaminophen on CGM glucose in an outpatient setting, Diabetes Care, 2015;38:e158-9.

85. Chamberlain JJ, Dopita D, Gilgen E, Neuman A, Impact of Frequent and Persistent Use of Continuous Glucose Monitoring (CGM) on Hypoglycemia Fear, Frequency of Emergency Medical Treatment, and SMBG Frequency After One Year, J Diabetes Sci Technol (Published online before print September 9, 2015, doi: 10.1177/1932296815604633).

86. Chamberlain J, Dopita D, Gilgen E, Persistence of continuous glucose monitoring use in a community setting 1 year after purchase, Clin Diabetes, 2013;31:106-9.

87. Hessler DP, Polonsky WH, Bowman F, Price D, The subjective experience of CGM-RT use: Comparing current users with ex-users, Diabetes, 2012;61:A215.

88. Polonsky WH, Hessler D, Perceived accuracy in continuous glucose monitoring: understanding the impact on patients, J Diabetes Sci Technol, 2015:9:339-41.

89. ClinicalTrials.gov, A Trial Comparing Continuous Glucose Monitoring With and Without Routine Blood Glucose Monitoring in Adults With Type 1 Diabetes (REPLACE-BG). Available at: https://clinicaltrials.gov/ct2/show/NCTO2258373 (accessed 27 December, 2015).

90. World Health Organization (WHO), Fact Sheets: Diabetes Available at: www.who.int/mediacentre/factsheets/fs312/en/ (accessed 24 December, 2015). 